\title{
Value chain and production cost optimization by integrating additive manufacturing in injection molding process chain
}

Tosello, Guido; Charalambis, Alessandro; Kerbache, Laoucine; Mischkot, Michael; Pedersen, David Bue; Calaon, Matteo; Hansen, Hans Nørgaard

Published in:

International Journal of Advanced Manufacturing Technology

Link to article, DOI:

$10.1007 / \mathrm{s} 00170-018-2762-7$

Publication date:

2019

Document Version

Peer reviewed version

Link back to DTU Orbit

Citation (APA):

Tosello, G., Charalambis, A., Kerbache, L., Mischkot, M., Pedersen, D. B., Calaon, M., \& Hansen, H. N. (2019). Value chain and production cost optimization by integrating additive manufacturing in injection molding process chain. International Journal of Advanced Manufacturing Technology, 100(1-4), 783-795.

https://doi.org/10.1007/s00170-018-2762-7

\section{General rights}

Copyright and moral rights for the publications made accessible in the public portal are retained by the authors and/or other copyright owners and it is a condition of accessing publications that users recognise and abide by the legal requirements associated with these rights.

- Users may download and print one copy of any publication from the public portal for the purpose of private study or research.

- You may not further distribute the material or use it for any profit-making activity or commercial gain

- You may freely distribute the URL identifying the publication in the public portal 


\title{
Value chain and production cost optimization by integrating additive manufacturing in injection moulding process chain
}

\author{
Guido Tosello $(*)^{1}$, Alessandro Charalambis ${ }^{1}$, Laoucine Kerbache², Michael Mischkot ${ }^{1}$, David Bue Pedersen ${ }^{1}$, \\ Matteo Calaon ${ }^{1}$, Hans Nørgaard Hansen ${ }^{1}$ \\ ${ }^{1}$ Department of Mechanical Engineering, Technical University of Denmark (DTU), Produktionstorvet, DTU building 427A, Kgs. Lyngby, 2800, Denmark \\ ${ }^{2}$ Department of Information's Systems and Operations Management, HEC Paris, rue de la Liberation 1, Jouy-en-Josas, 78350, France
}

$\left(^{*}\right)$ Corresponding Author guto@mek.dtu.dk $3+4545254893$

Additive Manufacturing (AM) can create considerable value when integrated into conventional manufacturing process chains. Tooling for new moulded product development as pilot case of integration of AM in the injection moulding process chain is investigated. The study shows that injection moulding based on AM for fabrication of polymer tool inserts is economically advantageous allowing $80 \%-90 \%$ production costs reduction as compared with a conventional tooling process chain based on machining. Fabrication of soft tools with AM results in a production lead-time reduction in the range of $60 \%-70 \%$ compared to the time required to machine mould inserts in brass or aluminium.

Additive Manufacturing, Injection Moulding, Tooling, Production Cost

\section{Introduction}

Additive manufacturing (AM) refers to a series of processes that have in common the use of a 3D CAD design to manufacture an object layer by layer. The origin of AM dates back to 1986 when it was first introduced the process of stereolithography (SL) or stereolithography apparatus (SLA) commercialized by 3D Systems for prototyping purposes.

To distinguish the use of layer based manufacturing technologies between their use for prototyping and end-use production, the ASTM International committee F2792 defined AM as the "process of joining materials to make parts from 3D model data, usually layer upon layer, as opposed to subtractive manufacturing and formative manufacturing methodologies" [1].

AM technologies have been characterized by an impressive double-digit growth, with a compound annual growth rate (CAGR) over the past 27 years of 26.2\% [2]. A large market for AM has been created in the past 20 years and a higher industrial adoption is foreseen. The market growth and the increasing use of AM have created a surrounding hype around the technology of being able to replace conventional manufacturing process.

This research's aim is to present how synergies between AM and conventional manufacturing processes can be achieved and as a consequence how it is possible to foster the adoption of AM in support of existing process chains for volume production.

In this work the focus will be on identifying how AM is able to add value if adopted to support the manufacturing process of injection moulding. Injection moulding is the most important process used to manufacture plastic products. Today injection moulding is used to process more than one-third of all thermoplastic materials worldwide and more than half of all polymer processing equipment is for injection moulding. The injection moulding process is highly suitable for the mass manufacturing of plastic products characterised by complex shapes and dimensional tolerances down to $0.1 \%$ to $1 \%$ of the component's dimension. The components of an injection moulding machine are the plasticising unit (where thermoplastic material is melted), clamping unit (to secure the closure of the mould halves to form a stably closed mould cavity), and the mould. An injection moulding cycle begins with the mould 
closure, followed by the injection of the polymer into the mould cavity by the reciprocating screw. While the cavity is filling the molten material starts to solidify and when the part is sufficiently cool, the mould opens and the part is ejected [3].

Following the increasing technological development of AM, its use for fabrication of mould inserts is increasingly becoming an industrially viable solution. Recent research has shown the potentials of integrating AM for production of plastic moulds inserts in terms of technological, operational and environmental benefits [4-7].

As far as plastic parts manufacturing, cost models on AM have been built so far solely on the assumption that AM could substitute injection moulding for accurate end-use parts production [8-12]. However, an analysis of the competitive and economic advantages of integrating AM into an injection moulding process chains by manufacturing the tool cavity in which the polymer melt is subsequently injected has not been performed so far. In response to this literature gap, this research addresses the advantages of additive manufacturing utilized in a synergistic rather than disruptive way to create additional value in the injection moulding process chain. When trying to use additive manufacturing to compete with the productivity of injection moulding by directly manufacture each component (i.e. AM as replacement of IM), this leads very quickly to an extremely high production cost for the AM technology for the manufacturing of just few parts, which is clearly not competitive (see point A in Figure 1). Instead, we envisage an integrated AM and IM process chain in which AM is used to produce part of the injection moulding tool creating the conditions for a more cost effective production. In this scenario, the production volume which is economically viable is from the hundreds of components up to the single digit thousands of parts (see point B in Figure 1). After this production volume there will be the transition of AM as support of IM towards a full injection moulding high volume production (se Figure 1).

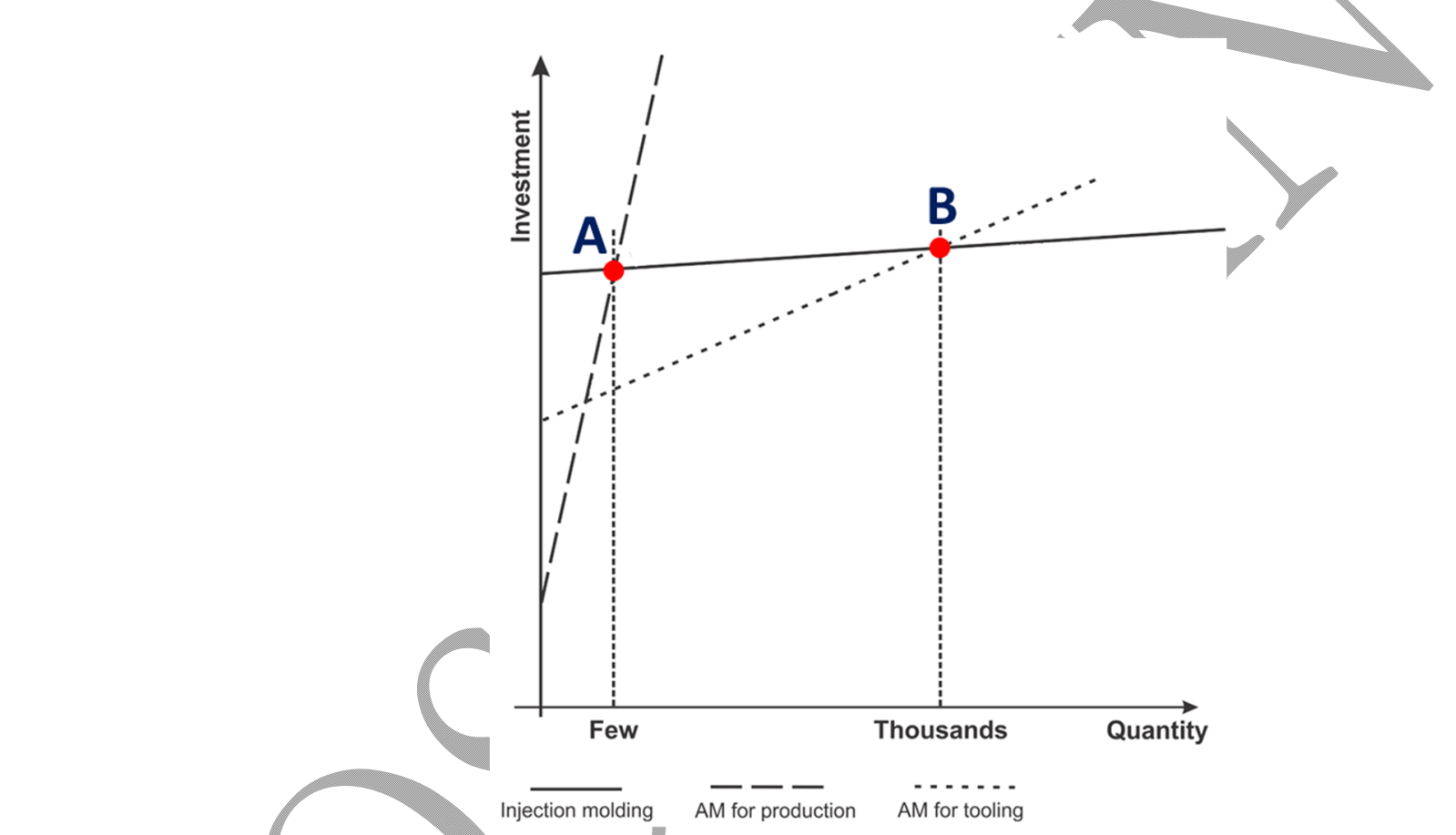

Figure 1. Cost curves of AM as injection moulding replacement or support technology for tooling.

\section{AM technology and additive manufactured part}

Digital Light Processing (DLP) is one of the most accurate AM technology available on the market [13-14]. A DLP machine is characterized by a vat filled with a photopolymer liquid resin and a horizontal platform that moves vertically on which the part is attached and lifted horizontally from the bottom to the top from the vat. A digital light projector, project the object geometry layerby-layer in the resin vat, which absorb the light and solidify the material following a photopolymerization process. Additive manufacturing on a DLP machine involves the following main steps:

(1) Pre-processing that includes setting the building environment by determining and choosing the appropriate material, layer thickness, and build style;

(2) Verify the correctness of the STL file and resolution of any errors;

(3) Setting the appropriate part orientation in the build platform by considering the trade-off between surface quality and building speed;

(4) Generation of necessary support structures for the part;

(5) Production step and specifically a top-down layer-by-layer manufacturing process.

(6) Post-processing that includes (a) cleaning the part from liquid resin; (b) removing support material and drying the part; (c) post curing the part into a UV light oven; (d) sanding, grinding or machining to achieve the desired surface finish. 
The part considered in this study is a mould insert equipped with micro features discussed in [6] to fit a four cavity mould and fabricated by the DLP AM technology. In particular, the DLP AM technology is here used for a soft tooling purpose, that is to make tools and tool inserts from prototype materials, for example from stereolithography resin. Prototype tooling is therefore characterized by quickly and easily made low-volume tools [15]. A drawing of the soft tooling insert in Figure 2a. In the injection moulding machine (see Figure $2 b$ ) is mounted the mould (see Figure $2 c$ ) where the additive manufactured inserts are assembled (see Figure $2 \mathrm{~d}$ ) and subsequently employed for the injection moulding pilot production. In Figure 2e an example of the injection moulded component (left) produced using the additive manufactured tool insert (right) are shown. The moulded test part is a cuboid with dimension of $20 \times 20 \times 2.7 \mathrm{~mm}^{3}$. In each injection moulding cycle four moulded parts are produced (see Figure $2 \mathrm{f}$ and $2 g)$.

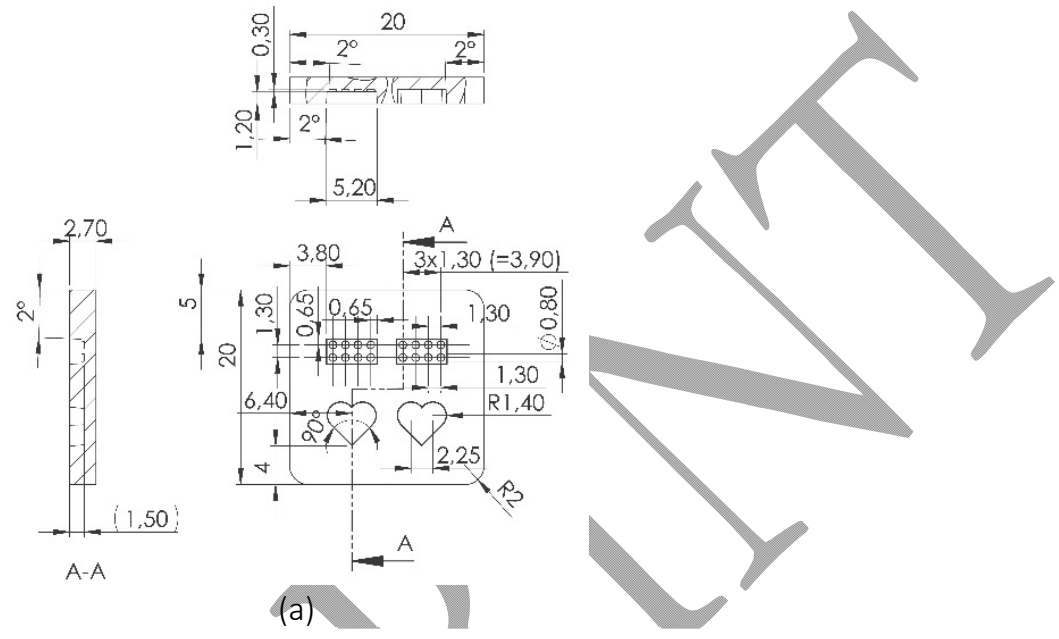

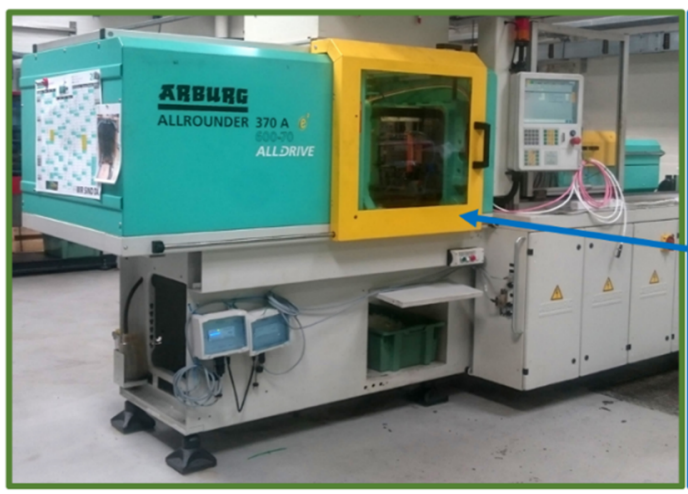

(b)

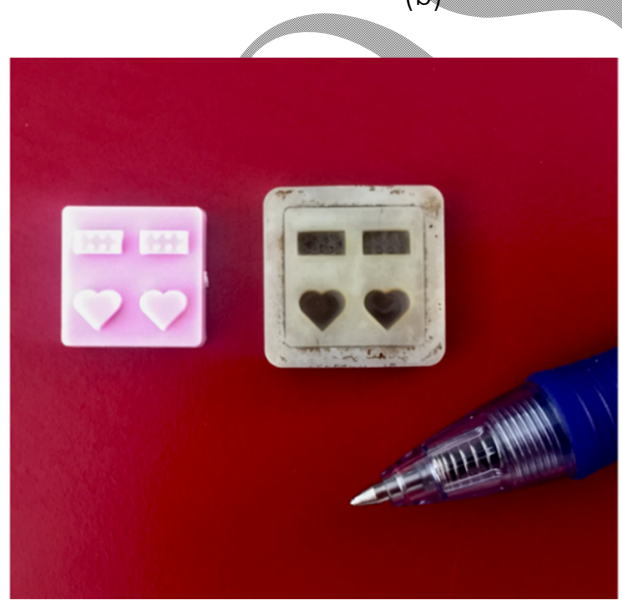

(e)

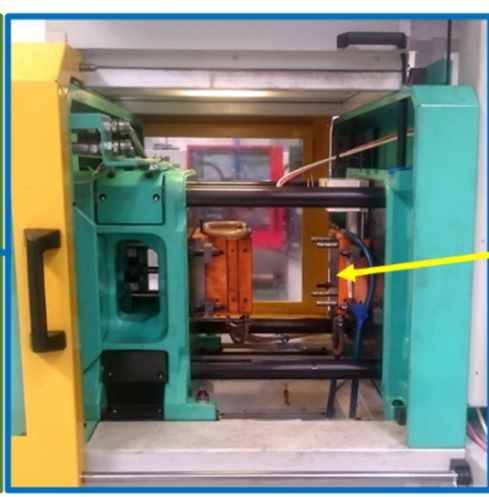

(c)

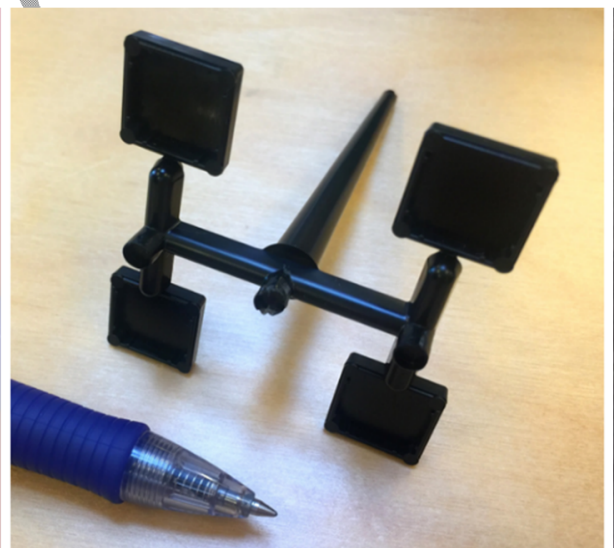

(f)

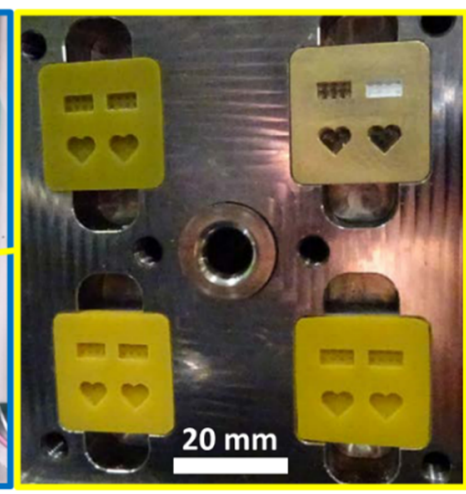

(d)

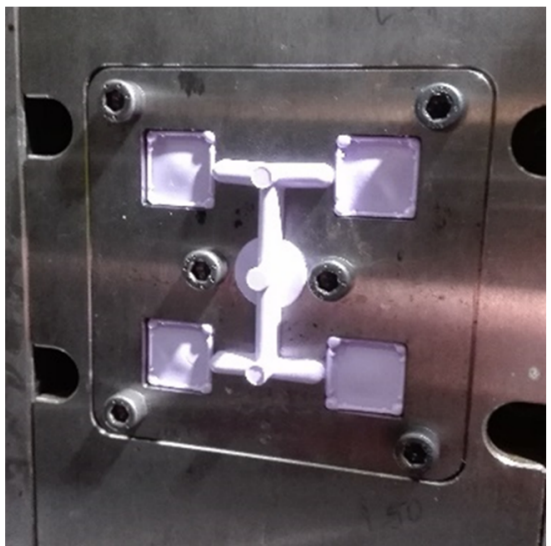

(g)

Figure 2. (a) Mould cavity insert considered in this study (adapted from [6]); (b) injection moulding machine; (c) injection moulding tool; (d) four additively manufactured inserts assembled into the moulding tool; (e) plastic part produced by injection moulding (left) using the tool with the additively manufactured insert (right); (f) moulded component produced in each moulding cycle including four part, runners, gates, sprue; (g) complete moulding in the mould before ejection. 


\section{Methodology}

To provide a thorough understanding of $\mathrm{AM}$ and its adoption in the industry is important to evaluate the technology from a cost/benefit perspective. Such analysis is the quantitative tool to be used by top-management for assessing the investment in the technology from a cost perspective [12]. Moreover, understanding the cost components that in the past mostly affected the price to fabricate an object reveals opportunities for the future. Therefore, it follows that the cost to manufacture an object is one of the factors that influence managers in deciding whether or not to implement a new technology [12].

AM cost models that are available in literature start under the idea that the technology is meant to replace conventional manufacturing. Instead, the aim of this paper is to thoroughly analyse the creation of synergies between AM and conventional manufacturing. Therefore, it is essential creating an understanding of what would be the cost of AM as supportive technology rather than a replacement for injection moulding.

Review of literature, cost models, application cases in companies belonging to different sectors, all reveal that when AM is used to replace injection moulding it is cost effective but only up to low production volumes [8-11]. Only few parts can be fabricated before AM becomes economically disadvantageous and manufacturers are forced to switch to conventional manufacturing technologies. Figure 1 shows the AM investment curve when used to replace injection moulding, and when it is integrated in the injection moulding process chain. Figure 3 shows a conventional cost per part comparison based on the use of injection moulding and AM technologies for direct part production.

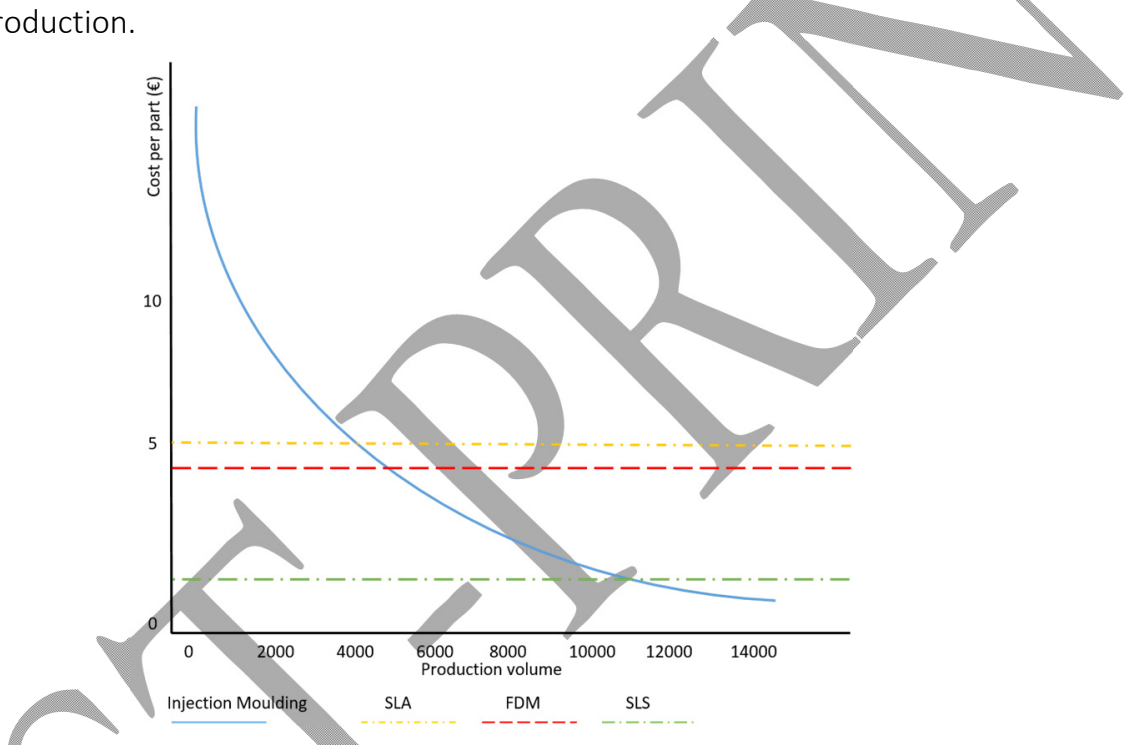

Figure 3. Comparison of cost per part between injection moulding, SLA, FDM (Fused Deposition Modelling), Selective Laser Sintering (SLS) when applied for direct part production (adapted from [9]).

AM for production of single units requires a low initial investment but the cost raises steeply with an increase of the production quantity. On the contrary, the injection moulding as fabrication method is characterized by a conspicuous initial investment, which is then followed by a relatively low cost to manufacture a part. Therefore, the break-even-point in this scenario is equal to a small batch manufactured. It follows that manufacturers have to switch quickly to the injection moulding in order to reach a cost effective solution for mass production.

The graph in Figure 1 also demonstrates that the transition curve of AM when applied to create synergies with conventional manufacturing is gradual compared to the steep transition curve of AM when it replaces injection moulding. Moreover, the integration of AM in the injection moulding process chain for fabrication of tooling, as it will be further analysed in this paper, points out that a much larger quantity can be manufactured. Application of AM for tooling production makes the technology cost effectiveness for much larger production quantities even though fabrication of complex and time lavish mould inserts require a higher initial investment. The discussion about the economics that characterize AM continue in the following sections where the cost model estimation for AM is presented.

\section{Additive Manufacturing Cost Model}

A cost model for the vat-photopolymerization technology, DLP [1], has not at this time been developed or discussed in literature yet. In this section, a cost estimation model for an insert manufactured with DLP technology is introduced.

The cost of an AM part manufactured with DLP technology is made up of five main cost elements: (a) pre-processing cost; (b) build cost; (c) material cost; (d) post-processing cost, and (e) overhead cost, as shown in Eq. (1): 


$$
C_{D L P}=C_{p p}+C_{p r}+C_{m}+C_{p p}+C_{o v}
$$

$C_{D L P}$ is the unit cost for parts fabricated on the DLP machine ( $\left.€ / p a r t\right), C_{p p}$ the unit cost for pre-processing (€/part), $C_{p r}$ the unit cost for manufacturing a part ( $€ /$ part $), C_{m}$ the unit cost for material ( $\left.€ / p a r t\right), C_{p p}$ the unit cost for post-processing ( $€ /$ part), and $C_{O}$ the unit cost of overheads (€/part) (see Table 1 ).

Equation (2) describes the cost for pre-processing activities that is affected among others by the part size, desired level of surface finish to achieve, material selection, and part orientation.

$$
C_{p p}=\frac{C_{O p}}{N} \times T_{S W}
$$

The hourly operator cost including overheads is defined as $C_{O p}(€ /$ hour), $N$ is the number of parts that can be printed in the same build and it depends on the size of the building envelope and the part orientation chosen. $T_{S W}$ (hour) is the time used to setup the print job and chose the initial setting.

In order to estimate the cost to print a part it is considered a simple mathematical relation between the machine cost per hour and the time spent to build a part as shown in Eq. (3):

$$
C_{\operatorname{Pr}}=C_{h}^{M} \times \frac{T_{B}}{N}
$$

where $C_{h}^{M}$ is the hourly cost of the DLP machine ( $€ /$ hour), $T_{B}$ is the printing time (hour). It is important to highlight that it is possible to incur in some errors during the printing of a part hence it is chosen to account for possible failures in the building through the use of the factor $\delta=[5 \%, 20 \%]$. Previous studies show that errors during the printing process can be linked with the experience of the operator that is handling the machine [14]. It was then chose to set the build error at $5 \%$ for an experienced operator and $20 \%$ for operators that do not have a high degree of experience with DLP. The error factor delta is introduced in the building time as follow: $T_{B}=T_{B} /(1-\delta)$. Considering that $N$ parts can be built in the same build, the time to complete the build is distributed over the number of parts manufactured simultaneously. Equation (4) describes the mathematical expression used to calculate the hourly cost of the machine.

$$
C_{h}^{M}=\frac{C_{I}}{Y} \times \frac{1}{\sigma \times H}
$$

$C_{I}$ is the investment cost in the machine ( $€$ ), $Y$ is the machine lifetime (year), $\sigma$ is a factor attributed to the machine utilization (\%), and $H$ is the total number of hours the machine can work in a year (hour/year).

Cost for the material used in the printing process is estimated starting with the price of material per volume unit and multiplied for the total volume of the part in the build as shown in the equation below.

$$
C_{m}=C_{l t}^{m} \times V_{b}
$$

$C_{l t}^{m}$ is the cost of material per litre used $(€ / I)$ and $V_{b}$ is the total volume of the build that includes the volume of a part, support structures and material wasted during the printing process. Based on the equipment employed in the considered case, the total volume filled by the part in the vat is around $70 \%$ of the total volume used in the build. Therefore, the total volume used in the build, $V_{b}$ can be estimated applying Eq. $(6 a, 6 b)$.

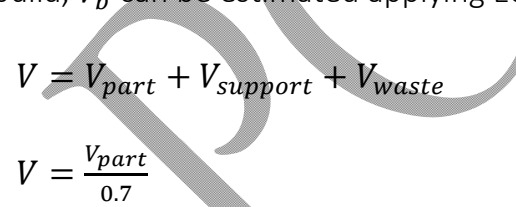

$V_{\text {support }}$ is the volume used for support structures in the build (in litres), $V_{\text {waste }}$ is the amount of material that is waste (in litres). Equation (7) breaks down the cost for post-processing activities, which includes removal of support material, post-curing, dry, and machining the part.

$$
C^{p p}=\frac{C_{O p} \times T^{p p}}{N}
$$

The time to post-process the part $T^{p p}$ (hour) is the sum of the time to remove support material $T_{S R}$, time to post-cure $T_{p c}$, time to dry the part $T_{p d}$ and the time required to machine the part $T_{M c}$ as shown in Eq. (8):

$$
T^{p p}=T_{S R}+\alpha \times\left(T_{p c}+T_{p d}+T_{M c}\right)
$$


Since the post-processing activities can be applied to more than one part at the same time, the total time used for post-processing is distributed over the number of parts that are printed in the same build, $N$. Moreover, to account for the time the operator is required to post-process DLP parts, the factor $\alpha(\%)$ is used.

The last cost component considered in the model is the cost for overheads. A previous cost model [8] did not considered the overhead cost by assuming that their contribution is less than $1 \%$ of the total unit cost. However, a more recent cost model [10] that was built based on the model of [9] discussed the importance of overheads cost that account for a $10 \%$ of the total unit cost. Therefore, it is chosen to have an accurate estimation of the cost of a part manufactured with DLP and overheads cost are introduced in the following equation:

$$
C_{o v}=\frac{C_{e l}+C_{S r}+C_{M e}}{N}
$$

However, it was chosen not to consider logistics costs due to the specific company setup of the industrial partner of this project where both AM and CNC machined mould inserts are manufactured in-house.

The cost for electricity usage $C_{e l}(€ /$ part) is calculated considering the amount of electricity consumed by the machine $E$ (KWh), the cost per kilowatt of electricity consumed $C_{e}(€ / \mathrm{KW})$ and divided by the number of parts manufactured in a hour $P$ (part/hour) as shown in Eq. (10).

$$
C_{e l}=\frac{E \times C_{e}}{P}
$$

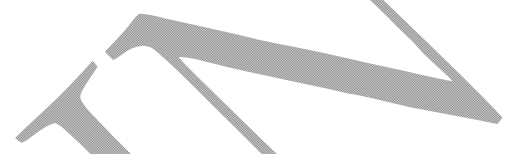

It follows that the cost to rent the facility $C_{S r}\left(€ /\right.$ part) is estimated by multiplying the amount of space used by the machine $S\left(\mathrm{~m}^{2}\right)$ and the cost for square meter used $C_{s}\left(€ / \mathrm{m}^{2}\right)$ and divide the whole by the number of hours the machine works in a year $(H \times \sigma)$, which is multiplied by the amount of parts manufactured in a hour $P$. Equation 11 summarizes what just described.

$$
C_{s r}=\frac{S \times C_{s}}{\sigma \times H} \times P
$$

Lastly, the maintenance cost $C_{M e}$ (€/part) is usually charged as a service cost from the machine manufacturer and equal to $10 \%$ of the machine purchase price. The yearly maintenance cost $C_{M e}^{y}(€ /$ year) is then distributed over the hours the machine works in a year $(\sigma \times H)$ and multiplied by the number of parts per hour $H$. Equation (12) show the mathematical equation used to estimate the maintenance cost per part.

$C_{M e}=\frac{C_{M e^{x P}}^{y}}{\sigma \times H}$

\section{Injection Moulding Cost Model}

The cost components of injection moulding were investigated to understand what are the main sources of costs to manufacture plastic moulded parts and quantify the impact of AM to lower the total cost. Three are the main cost elements that largely contribute to the cost of a moulded plastic part: (a) tool cost $C_{T}$; (b) material cost $C_{M}$; and (c) production cost $C_{P r}$ (all expressed in €/part), as shown in Eq. (13).

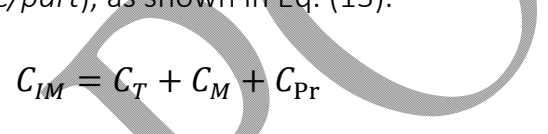

where $C_{I M}$ is the unit cost of a molded part (€/part), $C_{T}$ is the total tooling manufacturing cost per part ( $€ /$ part), $C_{M}$ is the material cost ( $€ /$ part), and $C_{P r}$ is the processing cost ( $€ /$ part).

Part complexity, size and geometry are among the main factors that affect the cost of a moulded part together with the material selection. Among those, the production volume is another factor that highly affects the cost per part as depreciating the highly expensive investment in tooling for a small or large volume can greatly influence the cost per part. Brass and aluminium mould inserts require an expensive investment hence at larger production volumes the ratio of cost due to tooling decreases as the investment is depreciated over a larger production volume.

Mould cost is mainly influenced by the cost of the mould base and the cost to machine the inserts. Based on the number of cavities in the mould, an equivalent number of inserts are machined. Inserts are dependent on the part size and geometry, and on the complexity of fabricating cavities and cores and the level of surface finish required. The mould cost is calculated as shown in Eq. (14): 


$$
C_{T}=\frac{C_{M B}}{L C}+\frac{C_{I n} \times n}{B}
$$

where $C_{M B}$ is the cost of a mold base $(€), C_{I n}$ is the cost to manufacture one insert ( $€$ /insert), $n$ is the number of cavities, $L C$ is the life cycle of the mould base (parts) and $B$ is the batch size or number of injection cycles for which the inserts is used for.

Material cost is a major factor to take into consideration. An appropriate selection of materials will positively affect the usability of final parts, and the life cycle of the inserts. Moulded part costs also depend on the choice of materials. The main components of material cost are the price per kilogram of material used and the weight of plastic material required to mould one part.

Part weight is calculated considering the sum of the part, runners, and sprue weights to account for the material used to mould the part, but also wasted for the runners and sprues as calculated in Eq. 15:

$$
C_{M}=C_{M_{K g}} \times W
$$

where $C_{M_{K g}}$ is material cost per kilogram of material used $(€ / \mathrm{kg})$, and $W$ is the total weight in kilogram.

Part processing cost is the sum of the expense related to the amount of time the operator spend to run the injection moulding machine and the cost of the machine per part. Eq. 16 determines the processing cost per part:

$$
C_{\mathrm{Pr}}=C_{h}+\frac{C_{m}}{\operatorname{Cap}_{h}}+\frac{\alpha \times C_{O}}{\operatorname{Cap}_{h}}
$$

where $C_{h}$ is the cost to set-up and run the injection molding machine ( $€ /$ part) and is calculated as the production of hourly operator cost and the sum of time to setup a mould and the time the machine is not running because the mould has been extracted, distributed over the batch size $\mathrm{B}$. $\mathrm{Cap}_{h}$ is the hourly capacity of the machine (in number of parts per hour) considering that a mould fabricated with $n$ cavities will produce $n$ parts over the cycle time. $C_{O}$ is the hourly cost of an operator ( $€$ /hour). The factor $\alpha$ is again used to account for the actual percentage of time the operator is involved in the use of the machine. According to industry standard typical of an injection moulding facility, an average utilization ( $\alpha$ ) of the workers equal to 20\%. Eq. (17) and (18) introduce the calculation of $C_{h}$ and $\operatorname{Cap}_{h}$ :

$$
\begin{aligned}
& C_{h}=\frac{\left(T_{S}+T_{D}\right) \times C_{O}}{B} \\
& \operatorname{Cap}_{h}=\frac{3600 \times n}{C T}
\end{aligned}
$$

To conclude, $T_{S}$ defines the time used to set-up the machine (in hours), while $T_{D}$ accounts for the time the machine is down for mould changeover or maintenance (in hours), and $C T$ is the cycle time of the process (in seconds).

Table 2 presents a detailed cost breakdown for injection moulding when the insert with micro features shown in Figure 3 is CNC machined and additively manufactured respectively.

\section{Results}

In the previous sections, a model to estimate the economics of AM aiming to develop a cost estimation method that describes the production costs associated with fabrication of inserts for injection moulding has been introduced. The objective of the economic analysis is to highlight the cost advantage of integrating AM in production environment aiming at decreasing the operational cost tied up with the cost of tooling for injection moulding.

The economic analysis of AM highlights the cost advantage of photopolymer inserts when used for low/medium production volumes. It is interesting to investigate how the situation would change for higher production volumes and up to what production volume AM results cost effective compared to CNC machining.

This section is structured presenting first a discussion of the cost advantage that are enabled by AM integration. The robustness of the cost estimation model is investigated considering how the adoption of AM would change in case the batch size is increased calculating the breakeven point between the two scenarios.

First, it is necessary to calculate the cost of a part produced with DLP technology as shown in Table 1. Seven different cost scenario based on actual manufacturing cases are presented to show the effects of the different cost elements on the final cost per part produced by the DLP AM technology. Secondly, the cost of inserts manufactured with DLP are used to calculate the cost per moulded part as shown in Table 2. For this purpose, the cost scenario D, representing a likely and intermediate case among the different cost settings considered, is used as input for the final cost of the moulded part.

An analysis of the cost components of an injection moulded part shows that the cost for CNC machining a tools account for $90 \%$ of the total unit cost (i.e. $C_{T}=13,31 €$ out of $C_{I M}=14,71 €$ ). The use of $A M$ for fabrication of soft tools decreases the tooling cost by $91 \%$ when the batch size is 100 moulded parts. Processing cost increases by $4 \%$ when AM inserts are used (from $1,38 €$ to $1,43 €$ ). 
The longer cooling time required by the photopolymer inserts to cool down efficiently the injection moulded part (50 s when using an AM insert instead of $20 \mathrm{~s}$ when using a CNC insert) is the main cause for the higher processing cost.

A break-even-analysis (BEA) was performed to assess and evaluate the economical trade-off of integrating AM in the IM process chain. Figure 4 shows that with a batch production size up to 110000 parts, the unit cost for parts moulded with the additively manufactured insert amounts to €0.06 and photopolymer inserts are favourable compared to machined inserts up to such production volume.

Table 1 Detailed cost breakdown for DLP manufactured parts considering different scenarios.

\begin{tabular}{|c|c|c|c|c|c|c|c|c|c|c|}
\hline \multirow{2}{*}{$\begin{array}{l}\text { Description } \\
\text { (unit) }\end{array}$} & \multirow{2}{*}{$\begin{array}{l}\text { Variable } \\
\text { symbol }\end{array}$} & \multicolumn{8}{|c|}{ Considered Values and Consequent Cost Scenario } & \multirow[b]{2}{*}{ Notes } \\
\hline & & $\begin{array}{l}{[\min ;} \\
\max ]\end{array}$ & A & B & C & $\mathrm{D}$ & $E$ & $\mathrm{~F}$ & G & \\
\hline $\begin{array}{l}\text { Parts per } \\
\text { build (N) }\end{array}$ & $N$ & {$[1 ; 15]$} & 15 & 4 & 3 & 3 & 2 & 2 & 1 & $\begin{array}{l}\text { Given by the size of the AM } \\
\text { machine's building envelope, } \\
\text { the part volume and the part } \\
\text { orientation }\end{array}$ \\
\hline $\begin{array}{l}\text { Operator cost } \\
\text { ( } € / \text { hour })\end{array}$ & $C_{O p}$ & 67,20 & 67,20 & 67,20 & 67,20 & 67,20 & 67,20 & 67,20 & 67,20 & $\begin{array}{l}\text { Hourly cost rate for an operator } \\
\text { including overheads and } \\
\text { administrative costs }\end{array}$ \\
\hline $\begin{array}{l}\text { Setup time } \\
\text { (min) }\end{array}$ & $T_{S W}$ & $\begin{array}{l}{[15 ;} \\
20]\end{array}$ & 15,00 & 17,78 & 15,98 & 15,97 & 17,82 & 19,08 & 20,00 & $\begin{array}{l}\text { Time to setup the print job, } \\
\text { chose the initial AM machine } \\
\text { settings, part orientation and } \\
\text { support structures (if needed) }\end{array}$ \\
\hline $\begin{array}{l}\text { Pre- } \\
\text { processing } \\
\text { cost }(€)\end{array}$ & $C_{p p}$ & $\begin{array}{l}{[1,12 ;} \\
22,40]\end{array}$ & 1,12 & 4,81 & 5,65 & 5,96 & 9,39 & 10,05 & 22,40 & $\begin{array}{l}\text { Cost to prepare the machine for } \\
\text { manufacturing the part } \\
\text { represented by the cost of the } \\
\text { operator to set up the AM } \\
\text { machine ready for production, } \\
\text { chose the correct part } \\
\text { orientation, material, level of } \\
\text { accuracy }\end{array}$ \\
\hline $\begin{array}{l}\text { Purchase } \\
\text { machine }(€)\end{array}$ & $C_{I}$ & 90.000 & 90.000 & 90.000 & 90.000 & 90.000 & 90.000 & 90.000 & 90.000 & $\begin{array}{l}\text { Cost for the investment to } \\
\text { purchase the DLP machine }\end{array}$ \\
\hline $\begin{array}{l}\text { Depreciation } \\
\text { time (year) }\end{array}$ & $Y$ & {$[3 ; 7]$} & 7 & 6 & 6 & 5 & 5 & 5 & 3 & $\begin{array}{l}\text { Number of year the machine } \\
\text { will be used before its } \\
\text { technology becomes obsolete }\end{array}$ \\
\hline Utilization (\%) & $\sigma$ & $\begin{array}{l}{[40 ;} \\
80]\end{array}$ & 80 & 64 & 76 & 63 & 68 & 62 & 40 & $\begin{array}{l}\text { Percentage of time the machine } \\
\text { is not idle }\end{array}$ \\
\hline $\begin{array}{l}\text { Hours per } \\
\text { year (hour) }\end{array}$ & $H$ & 8760 & 8760 & 8760 & 8760 & 8760 & 8760 & 8760 & 8760 & $\begin{array}{l}\text { Total number of hours the } \\
\text { machine could work in a year }\end{array}$ \\
\hline $\begin{array}{l}\text { Productivity } \\
\text { (part/hour) }\end{array}$ & $P$ & $\begin{array}{l}{[0,15} \\
2,25]\end{array}$ & 2,25 & 0,60 & 0,45 & 0,45 & 0,30 & 0,30 & 0,15 & $\begin{array}{l}\text { Number of parts that can be } \\
\text { manufactured in one hour }\end{array}$ \\
\hline $\begin{array}{l}\text { Cost of } \\
\text { material }(€ / I)\end{array}$ & $C_{M_{K g}}$ & 400 & 400 & 400 & 400 & 400 & 400 & 400 & 400 & $\begin{array}{l}\text { Material cost for the } \\
\text { photopolymer blend per volume } \\
\text { unit (litre) }\end{array}$ \\
\hline $\begin{array}{l}\text { Part volume } \\
\left(\mathrm{cm}^{3}\right)\end{array}$ & $V_{\text {part }}$ & 1,00 & 1,00 & 1,00 & 1,00 & 1,00 & 1,00 & 1,00 & 1,00 & $\begin{array}{l}\text { Volume occupied by the single } \\
\text { part (one insert) }\end{array}$ \\
\hline $\begin{array}{l}\text { Volume of } \\
\text { the build (I) }\end{array}$ & $V$ & $\begin{array}{r}{[1,5 \times} \\
10^{-3} \\
22,5 \times \\
\left.10^{-3}\right] \\
\end{array}$ & $\begin{array}{l}22,5 \\
\times 10^{-3}\end{array}$ & $\begin{array}{l}6,0 \\
\times 10^{-3}\end{array}$ & $\begin{array}{l}4,5 \\
\times 10^{-3}\end{array}$ & $\begin{array}{l}4,5 \\
\times 10^{-3}\end{array}$ & $\begin{array}{l}3,0 \\
\times 10^{-3}\end{array}$ & $\begin{array}{l}3,0 \\
\times 10^{-3}\end{array}$ & $\begin{array}{l}1,5 \\
\times 10^{-3}\end{array}$ & $\begin{array}{l}\text { Volume of the build considering } \\
\text { the number of parts that can be } \\
\text { manufactured simultaneously, } \\
\text { including support structures }\end{array}$ \\
\hline
\end{tabular}




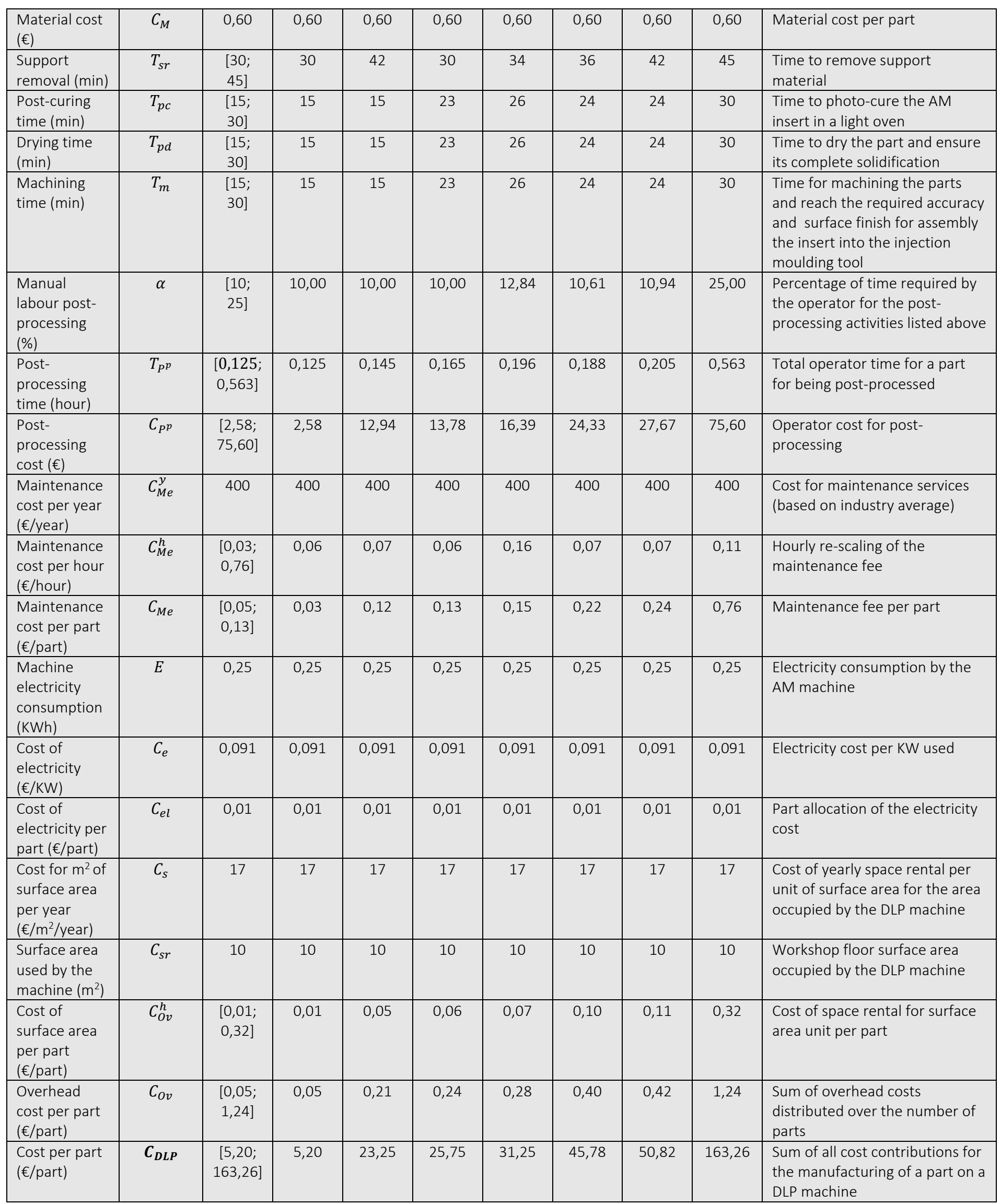


Table 2 Cost per moulded part using CNC and AM inserts for injection moulding tool. Notes: $\left({ }^{*}\right)$ this figure refers to the cost of a standard machining operation for the considered tooling insert design; $\left({ }^{* *}\right)$ this figure refers to cost scenario $D$ in Table 1.

\begin{tabular}{|c|c|c|c|c|}
\hline \multirow{2}{*}{$\begin{array}{c}\text { Cost } \\
\text { component }\end{array}$} & \multirow{2}{*}{$\begin{array}{l}\text { Variable } \\
\text { symbol }\end{array}$} & \multicolumn{2}{|c|}{ Value } & \multirow[t]{2}{*}{ Notes } \\
\hline & & CNC insert & AM insert & \\
\hline Mould base $(€)$ & $C_{M B}$ & $23.521,51$ & $23.521,51$ & $\begin{array}{l}\text { Investment to purchase a mould base for the assembly of } 4 \\
\text { inserts }\end{array}$ \\
\hline Mould block lifetime & $L C$ & 2.000 .000 & 2.000 .000 & $\begin{array}{l}\text { Expected life time of the mould base in number of } \\
\text { injection moulding cycles }\end{array}$ \\
\hline Insert (€/insert) & $C_{\text {In }}$ & $\begin{array}{c}332,66 \\
(*)\end{array}$ & $\begin{array}{c}31,25 \\
(* *)\end{array}$ & $\begin{array}{l}\text { Cost of one mould insert in aluminium or brass (CNC } \\
\text { machined insert) or in photopolymer (DLP AM technology) }\end{array}$ \\
\hline № of cavities (\#) & $n$ & 4 & 4 & Number of cavities in the injection mould tool \\
\hline $\begin{array}{l}\text { Batch size (parts } \\
\text { number) }\end{array}$ & $B$ & 100 & 100 & $\begin{array}{l}\text { Size of the batch in number of injection moulded parts for } \\
\text { which the mould's inserts are produced }\end{array}$ \\
\hline Tool cost ( $€ /$ part) & $C_{T}$ & 13,31 & 1,25 & Cost per part associated to the investment for tooling \\
\hline $\begin{array}{l}\text { Material per } \mathrm{Kg} \\
(€ / \mathrm{Kg})\end{array}$ & $C_{M_{K g}}$ & 1,74 & 1,74 & Cost of the injection moulding plastic per unit of mass \\
\hline Mass (g) & $W$ & 5,0 & 5,0 & $\begin{array}{l}\text { Mass of the complete moulded part produced in each } \\
\text { moulding cycle (including sprue, runners, gates) }\end{array}$ \\
\hline Material cost ( $€ /$ part) & $C_{M}$ & 0,009 & 0,009 & Cost per part of to the plastic used for injection moulding \\
\hline Setup time (hour) & $T_{S}$ & 1 & 1 & $\begin{array}{l}\text { Time to setup the injection moulding machine to start } \\
\text { production }\end{array}$ \\
\hline Down time (hour) & $T_{D}$ & 1 & 1 & $\begin{array}{l}\text { Average time the machine is idle due to mould and/or } \\
\text { insert changeover, scheduled or unpredicted maintenance } \\
\text { during a pilot production of } 100 \text { parts }\end{array}$ \\
\hline $\begin{array}{l}\text { Operator cost } \\
(€ / \text { hour })\end{array}$ & $C_{O}$ & 67,2 & 67,2 & $\begin{array}{l}\text { Hourly cost of the operator working and supervising the } \\
\text { injection moulding machine during pilot production } \\
\text { (including overheads and administrative costs) }\end{array}$ \\
\hline Handling cost ( $€ /$ part) & $C_{h}$ & 1,344 & 1,344 & $\begin{array}{l}\text { Cost per part of set-up and machine idle time calculated as } \\
\text { hourly operator cost and distributed over the batch size B }\end{array}$ \\
\hline Cycle time (s) & $C T$ & 20 & 50 & $\begin{array}{l}\text { Injection moulding cycle time taking in consideration } \\
\text { mould closing/clamp, filling phase, packing phase, cooling } \\
\text { phase, mould opening and part ejection }\end{array}$ \\
\hline $\begin{array}{l}\text { Hourly capacity } \\
\text { (part/h) }\end{array}$ & $\operatorname{Cap}_{h}$ & 720 & 288 & $\begin{array}{l}\text { Machine hourly productivity based on cycle time and } \\
\text { number of mould cavities/mould inserts }\end{array}$ \\
\hline $\begin{array}{l}\text { Injection moulding } \\
\text { machine cost }(€ / h)\end{array}$ & $C_{m}$ & 12,6 & 12,6 & Hourly cost of the injection moulding machine \\
\hline $\begin{array}{l}\text { Production cost } \\
\text { (€/part) }\end{array}$ & $C_{P r}$ & 1,38 & 1,43 & $\begin{array}{l}\text { Production cost per part (considering a pilot production } \\
\text { batch of } 100 \text { parts) }\end{array}$ \\
\hline Cost per part (€/part) & $C_{I M}$ & 14,70 & 2,69 & $\begin{array}{l}\text { Cost of a part moulded with an insert produced by CNC } \\
\text { machining or additively manufacturing respectively }\end{array}$ \\
\hline
\end{tabular}

This analysis shows that is possible to mould parts up to medium production volumes without incurring in extra operating costs due to increase cost of tooling. For larger production volumes that are common in mass production and reach the millions of cycles, it is advisable to switch tooling technology and use machined inserts in tool steel. The longer lifetime of the machined inserts allows depreciating the tooling costs over a larger production volume and decrease the number of changeover needed by the AM inserts. Instead, he cost advantages linked to moulding small/medium production series with photopolymer inserts prove and show the potential cost savings in supporting IM with AM.

One of the factors that influences the BEA of AM inserts is the size of the insert, which acts as a production constraint in fabricating a high number of inserts in the same AM build batch. Moreover, the size of AM inserts and the material used to produce them allow for a shorter amount of time spent for post processing activities that decreases the overall cost of additively manufactured parts. 


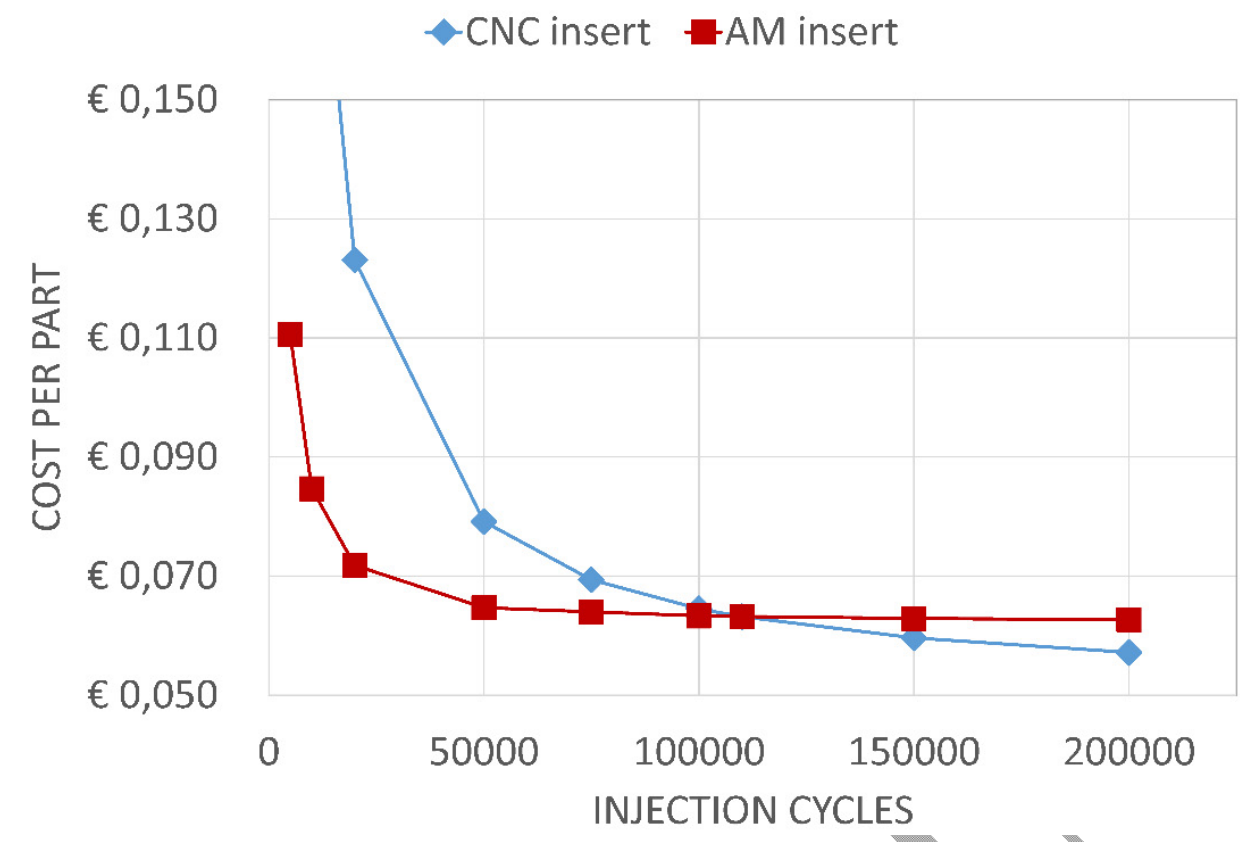

Figure 4. Break-Even-Analysis of AM and machined inserts for injection moulding.

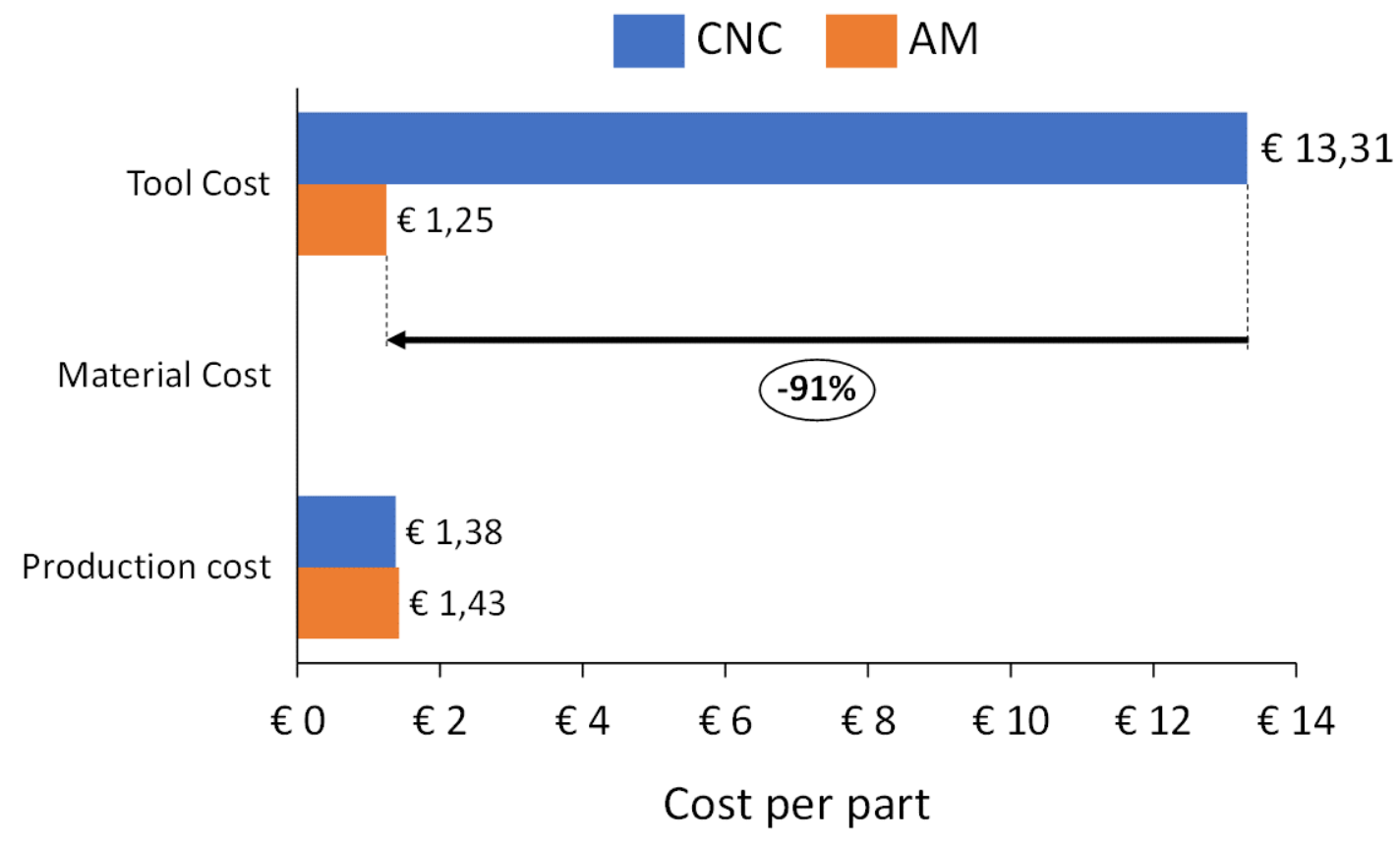

Figure 5. Cost per plastic part comparison injection moulded with CNC machined and AM inserts (batch size: 100 parts).

\section{Discussion}

The cost model proves the potential cost savings in applying AM inserts in injection moulding serial production when small batches of parts are to be moulded. For small batch with size up to 110000 injection cycles, the largest cost component is the investment in tooling. Figure 5 shows how the three injection moulding cost components (tool, material and processing costs) affect the total cost per part when inserts are machined or fabricated with AM. For a part moulded with the insert manufactured in brass or aluminium by CNC machining, the cost for tooling can be up to $80-90 \%$ of the total cost per part, while with AM inserts is $54 \%$ of the total cost in the considered case when AM is used for prototyping and the production batch is equal to 100 shots (i.e. $C_{T}=1,25$ $€$ out of $\left.C_{I M}=2,69 €\right)$. The final cost part decreases by $82 \%$ from $14.71 €$ for parts moulded with a CNC insert down to $2.69 €$ for parts moulded with an AM inserts (see Table 2). Increasing the batch size and consequently changing the technology for final tool production of larger moulding volumes (100000 parts or higher) allows to depreciate the cost of tooling over a higher number of 
parts. When increasing the batch size, it is critical to consider the tool lifetime, which for the brass or aluminium inserts can reach 2000000 shots, while for the AM inserts has reached in this study a lifetime of 10000 injection moulding cycles.

Moreover, the increase in processing cost in AM inserts is due to the longer cycle time required to efficiently cool down the insert, which is 2.5 times higher than the cycle time observed with brass inserts. The longer cycle time when parts are moulded using the AM insert has to be taken into account in the cost model to assess by how much the total production lead-time is affected by such longer cycle time over the long run. A greater advantage can be obtained in case the integration of AM for inserts production reduces the manufacturing lead-time for new parts and speed the product development phase.

The simulation case-scenario showed that in case AM inserts are used, the time required to manufacture the necessary amount of inserts, carry out the post-processing activities, assemble the inserts into a 4 cavity mould and perform 100 injection shots is equal to 61.7 hours. When the inserts are CNC machined more than twice the time is required since the observed lead-time was equal to 182.6 hours. Therefore, it is possible to notice that using AM inserts leads to a $66 \%$ lead-time reduction in the product development phase. Such lead-time reduction means that for a low production volume typical of the product development phase, integrating AM can reduce the manufacturing lead-time by at least five days and streamline the entire process.

Lead-time reduction in the pilot production leads to a higher operational effectiveness that is transformed in a competitive and cost advantage. Through the reduction of the time required to fabricate inserts, it is possible to quickly test new part designs and evaluate them in less than half of the time that it is required with conventional tooling technologies. Even though the cycle time required to mould parts when AM inserts are used 2.5 times higher due to the longer cooling time that is necessary to prevent thermal aging of the inserts, the time savings in the overall process are remarkable. Moreover, if it is taken into consideration that few design iterations are usually necessary before the final version is obtained, then the advantage of using AM inserts is even greater.

\section{Conclusion}

This research contributes to the analysis and development of additive manufacturing adoption within the conventional manufacturing process of injection moulding. It is of a particular interest in order to facilitate companies to research how to exploit the advantages that AM can offer. This article elaborates on the possible synergies between AM and conventional manufacturing to create added value by decreasing operational cost in the pilot production, particularly useful in the product development phase.

The impact of layer manufacturing technologies has been a largely discussed topic in the literature, where it has been argued that the way products have been manufactured until now it is meant to be overturned by AM. However, this work focused on an alternative scenario in which AM is not conceived as a disruptive technology but instead as a set of processes that have the potential to improve a conventional production process (i.e. injection moulding in this case) instead of replacing it.

Alongside, this research has quantified the benefits of additive manufacturing integration for value creation with respect to cost and lead-time reduction. In this way, the work represents a source of novelty in the practice of analysing additive manufacturing to optimize a supply chain while considering at the same time the value chain. Such analysis helps to identify the primary key trends in additive manufacturing adoption and the main challenges that organizations need to address in order to determine how additive manufacturing can deliver value to the production process chain.

One of the most important points that emerged from the analysis is the impact of additive manufacturing in increasing the operational efficiency and substantially decreasing the manufacturing cost. These aspects have been exemplified in this work through the integration of additive manufacturing for soft tooling in an injection moulding process chain.

The research has demonstrated the possibility to reduce manufacturing cost in terms of cost per part by $82 \%$ (from $14,70 € /$ part down to 2,69 $€ /$ part in case of a batch of 100 parts) and streamline the whole product development phase by obtaining a much faster and flexible process chain with a considerably shorter lead-time. On-demand production of injection moulding tools is now a reality. Through the use of photopolymer inserts produced by DLP it is possible to reduce the production lead time of tooling by $66 \%$. The average weeklong time required to machine inserts can be substituted by a two days lead-time when additive manufacturing is used. Such faster and more flexible product development phase allows achieving a higher level of operational flexibility through the creation of a quicker, cost effective and more agile production system. New part designs can be tested quickly, hence manufacturing companies have the possibility to speed their time-to-market reducing the whole product development phase.

Moreover, the investment in tooling is remarkably reduced as the cost for manufacturing mould inserts are extremely decreased. The inserts manufacturing cost is reduced from €1331 to €125 (i.e. 91\% decrease) of the CNC machined insert and AM insert respectively. On-demand production of injection moulding tools is now a reality and the investment in tooling is remarkably decreased as the cost for manufacturing mould inserts is substantially decreased.

Even though AM has the potential to optimize the operational efficiency of a firm, it is important to highlight that the current technological limitations can still slow down its adoption in some department and areas of the job floor. A reflection on the current restrictions of the technology is necessary to correctly establish where and how layer manufacturing techniques can be applied, for example determining their suitability when more restrictive production requirements and smaller product tolerance specifications are defined. Consequently, the main areas where the technology will need to improve are identified and discussed throughout the cost estimation model, which highlights the key cost components and their impact on production cost and lead-time. 


\section{Acknowledgments}

The Manufacturing Academy of Denmark (MADE) project (http://en.made.dk/), WorkPackage 3 "Additive Manufacturing and Advanced Manufacturing Technologies", funded by Innovation Fund Denmark (https://innovationsfonden.dk/en), and the Marie og M. B. Richter's Fond (Denmark) are acknowledged for supporting the present research. The authors thank the HEC Paris Business School (France) for the partial financial support to conduct this research.

\section{References}

[1] ASTM International, 2015, Standard Terminology for Additive Manufacturing Technologies - General Principles - Terminology, ISO/ASTM 52900, vol. i, pp. 1-9.

[2] Wohlers Associates, 2017, Wohlers Report 2017 - 3D Printing and Additive Manufacturing State of the Industry.

[3] Osswald, T. A., Baur, E., Brinkmann, S., Oberbach, K., Schmachtenberg, E., 2006, International Plastics Handbook - The Resource for Plastics Engineers, Publisher: Carl Hanser Verlag GmbH \& Co. KG, ISBN: 978-3-446-22905-1, https://doi.org/10.3139/9783446407923

[4] Zhang, Y., Pedersen, D. B., Segebrecht, A. G., Mischkot, M., Tosello, G., 2017, A Soft Tooling process chain employing Additive Manufacturing for injection molding of a 3D component with micro pillars, Journal of Manufacturing Processes, Vol. 27, 138-144, https://doi.org/10.1016/j.jmapro.2017.04.027

[5] Mischkot, M., Tosello, G., Nielsen, D. K. Y., Pedersen, D. B., Zhang, Y., Hofstätter, T., Herbin, L., Hansen, H. N., 2017, Injection Moulding Pilot Production: Performance Assessment of Tooling Process Chains Based on Tool Inserts.Made From Brass and a 3D Printed Photopolymer, in Annual Technical Conference (ANTEC2017) of the Society of Plastic Engineers, Anaheim, CA (USA), 2017, 5 pages.

[6] Hofstätter, T., Bey, N., Mischkot, M., Stotz, P. M., Pedersen, D. B., Tosello, G., Hansen, H. N., 2017, Integration of Fiber-Reinforced Polymers in a Life Cycle Assessment of Injection Molding Process Chains with Additive Manufacturing, in M. Meboldt and C. Klahn (eds.), Industrializing Additive Manufacturing - AM in Products and Applications - AMPA2017, pp. 289-297, DOI 10.1007/978-3319-66866-6 27

[7] Thompson, M. K., Stolfi, A., Mischkot, M., 2016, Process chain modeling and selection in an additive manufacturing context, CIRP Journal of Manufacturing Science and Technology, vol. 12, pp. 25-34.

[8] Franchetti, M., Kress, C., 2016, An economic analysis comparing the cost feasibility of replacing injection molding processes with emerging additive manufacturing techniques, Int. J. Adv. Manuf. Technol., pp. 2573-2579.

[9] Hopkinson, N., Dicknes, P., 2003, Analysis of rapid manufacturing using layer manufacturing processes for production, Proc. Inst. Mech. Eng. Part C J. Mech. Eng. Sci., vol. 217, no. 1, pp. 31-39.

[10] Ruffo, M., Tuck, C., Hague, R., 2006, Cost estimation for rapid manufacturing-laser sintering production for low to medium volumes, 220/9:1417-1427.

[11] Atzeni, E., Iuliano, L., Minetola, P., Salmi, A., 2010, Redesign and cost estimation of rapid manufactured plastic parts, Rapid Prototyp. J., vol. 16, no. 5, pp. 308-317.

[12] Schniederjans, D. G., 2017, Adoption of 3D-printing technologies in manufacturing: A survey analysis, Int. J. Prod. Econ., vol. 183, pp. 287-298, 2017.

[12] Wohlers, , T. T., Caffrey, T., Campbell, R. T., 2016, Wohlers Report 2016: 3D Printing and Additive Manufacturing State of the Industry: Annual Worldwide Progress Report. Wohlers Associates.

[13] Gibson, I., Rosen, D., Stucker, B., 2014, Additive manufacturing technologies: 3D printing, rapid prototyping, and direct digital manufacturing. Springer.

[14] Thompson, M. K., Moroni, G., Vaneker, T., Fadel, G., Campbell, R. I., Gibson, I., Bernard, A., Schulz, J., Graf, P., Ahuja, B., Martina, F., 2016, Design for Additive Manufacturing: Trends, opportunities, considerations, and constraints, CIRP Annals - Manufactuing Technology, 65/2:737-760.

[15] Gebhardt, A., Hötter, J.-S., 2016, Additive Manufacturing - 3D Printing for Prototyping and Manufacturing, Publisher: Carl Hanser Verlag GmbH\& Co. KG, ISBN: 978-1-56990-582-1, https://doi.org/10.3139/9781569905838 